\title{
Stressors and Coping Strategies among Faculty of Nursing Students at AL -Hussein Bin Talal University- Jordan
}

\author{
Sayead , Sh., El- A; Mohamed, I., I ; El Nawafleh , H., \& Address, P., \\ Assistant prof. Psychiatric nursing, Faculty of Nursing, Assiut University- Egypt \\ Associate Prof., Faculty of Princess Aesheh Bint Al-Hussein for Nursing, AL -Hussein Bin Talal University-Jordan \\ Permanent address, Assistant Prof. Medical- Surgical Nursing Faculty of Nursing, Assiut University-Egypt \\ Assistant prof. Community health nursing, Faculty of Princess Aesheh Bint Al-Hussein for Nursing, AL -Hussein \\ Bin Talal University-Jordan
}

\begin{abstract}
:
Stress and the identification of potential stressors among nursing students have received much attention in the literature. Student perception of high stress levels can lead to poor academic performance, depression, attrition and serious health problems. Effective coping strategies facilitate the return to a balanced state, reducing the negative effects of stress. The study aimed to recognize various stressors among faculty of nursing students and to explore various coping strategies utilized by students to deal with stressors. A descriptive comparative design was utilized in this study. Setting: The study was conducted at Faculty of Princess Aesheh Bint Al-Hussein for Nursing- AL Hussein Bin Talal University in Jordan. Subjects: The subjects comprised of all students from $1^{\text {st }}$ to $4^{\text {th }}$ year who agreed to participate in the study. The total number was 175 students; 62 of them were from first grade, 40 from second grade, 36 from third grade and 37 from fourth grade. Tools: Student Stress Survey and the Adolescent Coping Orientation for Problem Experiences Inventory (ACOPE) were used to achieve the aims. Result: The most common intrapersonal sources of stress were new responsibilities $(88.0 \%)$ and change in sleeping habits (73.7\%) and the most common academic sources of stress were lower grade than anticipated (86.9\%) and increased class workload (86.3\%). Concerning the environmental sources of stress, students reported car trouble $(71.4 \%)$ and messy living conditions $(64.6 \%)$ and the most common interpersonal source of stress was "change in social activities" (61.7\%). Statistically significant differences were found between various grade students in relation to interpersonal and environmental sources of stress ( $p$ value was 0.043 and 0.013). As regards coping strategies, $56.0 \%$ of the sample reported using pray to cope with stressors, $54.3 \%$ and $53.1 \%$ reported try to keep up friendships or make new friends and say nice things to others often or always and $51.4 \%$ talk to a minister/priest/ rabbi. There are statistically significant differences between various grade students regarding use of seeking diversions and seeking professional support as coping strategies ( $\mathrm{p}$ value $=0.029 \& 0.014$ ) respectively. Conclusion: Intrapersonal and academic stressors were the common stressors among faculty of nursing students. Praying, keeping up friendships or making new friends were the common used coping strategies to deal with stressors. There were statistically significant differences between various grade students regarding stressors and use of coping strategies. Recommendation: Psycho educational program about stress management techniques is essential to help students manage their stressors effectively.
\end{abstract}

\section{Key Words: Stress, Stressors, Coping Strategies, Faculty Of Nursing Students}

\section{Introduction:}

Stress has been identified as a 20th century disease and has been viewed as a complex and dynamic transaction between individuals and their environments (Evans \& Kelly, 2004). In this respect, Pender 2002 reported that, stress is perceived as a challenge, a threat, or a danger, can have both positive and negative effects. Similarly, (Day \& Livingstone, 2004) stated that, stress can be regarded as a psychological threat, in which the individual perceives a situation as a potential threat. Stress could be defined simply as the rate of wear and tear on the body systems caused by life (Stranks, 2005). It occurs when a person has difficulty dealing with life situations, problems and goals (Videbeck, 2007). Stress has physical, emotional, and cognitive effects. Although everybody has the capacity to adapt to stress, not everyone responds to similar stressors exactly the same (Timby, 2008). Stressors can be broadly defined as situations or events that have the potential to affect health outcomes (Barling, 1990). A stressor can be social, physiological or environmental origin (Sadock \& Kaplan, 2007).

College students are prone to stress due to the transitional nature of college life. Academic stress among college students has been a topic of interest for many years. College students, especially freshmen, are particularly prone to stress due to the 
transitional nature of college life. For example, many college students move away from home for the first time, which can necessitate leaving all previously learned support systems such as parents, siblings and high school friends. Students may need to develop entirely new social contacts and are expected to take responsibility for their own needs. They may have difficulty adjusting to more rigorous academic expectations and the need to learn to deal with individuals of differing cultures and beliefs. Thus, stress may result from being separated from home for the first time, the transition from a personal to an impersonal academic environment, and the very structure of the academic experience at the college level (Shields, 2001). Significant changes in living conditions, the novel demands of the college academic environment, and the large change in social surroundings are just a few of the potential sources of stress for a college student (Tamina,1998).

Stress among university students has been a topic of interest for researchers and teachers for many years because it affects not only their academic performance but also their physiological and psychological health. Conducting specific stresstraining programmers' for male and female students will help in reducing stress levels (Shaher 2012).

High levels of stress are believed to affect students' health and academic functions. If the stress is not dealt with effectively, feelings of loneliness, nervousness, sleeplessness and worrying may result. College students experience high stress at predictable times each semester due to academic commitments, financial pressures, and lack of time management skills. Moreover, regardless of year in school, college students often deal with pressures related to finding a job or a potential life partner. These stressors do not cause anxiety or tension by themselves. Instead, stress results from the interaction between stressors and the individual's perception and reaction to those stressors. Other potential sources of stress for college students include excessive homework, unclear assignments, and uncomfortable classrooms. In addition to academic requirements, relations with faculty members and time pressures may also be sources of stress (Misra \& McKean, 2000).

Nursing involves activities and interpersonal relationships that are often stressful. Caring for clients who are experiencing high levels of anxiety can be stress provoking for nurses (White, 2000).

Stress and the identification of potential stressors among nursing students have received much attention in the literature (Nicholl \& Timmins, 2005). Nursing students have the same academic stressors as other college students, such as midterm and final examinations, research papers and other assignments (Evans, 2004). In addition, nursing students experience a clinical component, which is highly stressful. Students have a large amount of preparatory work before their clinical assignments. They often must travel long distances to clinical sites and use highly technical equipment Mahat, 1998\& Shriver, 2000). More over, they must perform procedures that can cause serious harm to their patients, thus enhancing their fear of making mistakes. Studies indicate that nursing students may be more prone to stress than other students.

Sources of stress may be interpersonal, intrapersonal, academic or environmental. Interpersonal sources as a fight with a boyfriend or girlfriend or trouble with parents; intrapersonal sources result from internal sources, such as changes in eating or sleeping habits. Academic sources arise from school-related activities and issues, such as increased class workload or transferring between schools. Environmental sources result from problems in the environment outside of academics, such as car or computer problems and crowded traffic (Seyedfatemi et al., 2007).

Coping has been viewed as a stabilizing factor that may assist individuals in maintaining psychosocial adaptation during stressful events. Thus, the actual reaction to an environmental event may be as important as the event itself (Robin Walton, 2007). Coping responses can be described as positive or negative and as reactive (i.e. reacting to an individual's own thoughts and feelings) or active (dealing with actual stressful situations or events). Active or reactive coping responses can be positive or negative, depending on the situation and the content of the response [Shields, 2001].

Failure to resolve student stress in the long term could have serious professional and personal consequences as stated by (Nicholl \& Timmins, 2005). Although students cannot avoid these stressors, their ability to adjust to demands and cope with these stressors are important in achieving success in the college academic and social environments (Tamina, 1998). Therefore, studying student stress and the methods students use to deal with it can have important implications for higher education administrators (Shriver, 2000).

Student perception of high stress levels can lead to poor academic performance, depression, attrition and serious health problems. Methods to reduce student stress often include effective time management, social support, positive reappraisal, and engagement in leisure pursuits (Misra \& McKean, 2000). In this respect, Seyedfatemi et al., 2007 reported that, effective coping strategies facilitate the return to a balanced state, reducing the negative effects of stress. 


\section{Aims of study}

This study aimed to recognize various stressors among faculty of nursing students and to explore various coping strategies used by students to deal with

Material and Method:

Design: A descriptive comparative design was utilized in this study.

Setting: The study was conducted at Faculty of Princess Aesheh Bint Al-Hussein for Nursing- AL Hussein Bin Talal University.

Subjects: The subjects comprised of all students from $1^{\text {st }}$ to $4^{\text {th }}$ year who agreed to participate in the study at the previous setting. The total number was 175 students; 62 of them were from first grade, 40 from second grade, 36 from third grade and 37 from fourth grade.

Tools: Two instruments were used to achieve the aims, The Student Stress Survey and the Adolescent Coping Orientation for Problem Experiences Inventory (ACOPE). The Student Stress Survey, based on the Student Stress Scale (Insel, \& Roth, 1985) cited in Seyedfatemi et al., 2007, was used to measure stressors. This survey consists of 40 items divided into 4 categories of potential sources of stress: 6 items representing interpersonal sources of stress, 16 representing intrapersonal sources of stress, 8 representing academic sources of stress, and 10 representing environmental sources of stress. Respondents provided a "Yes" or "No" answer to each item they had experienced during the current school year.

ACOPE was utilized to assess coping strategies among adolescents, and was initially developed and tested with a sample of Midwestern junior and senior high school students by Patterson and McCubbin (1987) cited in Seyedfatemi et al., 2007. This scale has 54 items in 12 areas, each with Likert-scale responses (i.e. Never 1", "seldom 2", "Sometimes 3", "Often 4" and "Most of the time 5"): 6 items representing ventilating of feelings, 4 of relaxing, 8 of seeking diversions, 6 of developing self-reliance, 6 of developing social support, 6 of solving family problems, 5 of avoiding problems, 3 of seeking spiritual support, 2 of investing in close friends, 2 of seeking professional support, 4 of engaging in demanding activities, and 2 of being humorous. The previous tools were translated into Arabic language to suit students' culture and validity was done for both tools by jury of 5 psychiatric nursing staff and necessary modifications were done.

\section{Procedure}

-An official permission was granted from authoritarian personnel to carry out study.
- The purpose of the study was explained to students and verbal consent was taken from students who agreed to participate in the study.

Pilot study: The pilot study was done on 15 students to test clarity and applicability of tools. Those students were included in the total sample because there was no any modification was done for both tools.

Data collection: The data were collected through distribution of the tools for students after explanation of the aim of study during the second semester of the academic year 2011- 2012 in the faculty of Princess Aesheh Bint Al-Hussein for Nursing- AL -Hussein Bin Talal University.

Ethical consideration: Ethical approval for the protocol of research was obtained

Research Committee in the faculty of Princess Aesheh Bint Al-Hussein for Nursing- AL -Hussein Bin Talal University. The researchers obtained informed consent for participation from students after they were provided with a detailed description of the study and were assured of the confidentiality of information obtained. Students were informed that participation in the study was voluntary and that they had the freedom to participate or not.

\section{Statistical Analysis:}

The collected data were coded, categorized, and then analyzed using the statistical package for social science (SPSS) version 16. Descriptive statistics were calculated as frequency, percentage, mean, standard deviation. ANOVA test was used. Probability (pvalue) is considered significant at or less than 0.05 


\section{Results}

Table (1): Socio demographic characteristics of the studied students

\begin{tabular}{|c|c|c|}
\hline Variables & No. $(n=175)$ & $\%$ \\
\hline \multicolumn{3}{|l|}{ Age: (years) } \\
\hline $18-19$ & 62 & 35.4 \\
\hline $20-21$ & 81 & 46.3 \\
\hline 22 or more & 32 & 18.3 \\
\hline Mean \pm SD (Range) & \multicolumn{2}{|c|}{$20.34 \pm 2.05(18-30)$} \\
\hline \multicolumn{3}{|l|}{ Sex: } \\
\hline Male & 16 & 9.1 \\
\hline Female & 159 & 90.9 \\
\hline \multicolumn{3}{|l|}{ Marital status: } \\
\hline Single & 165 & 94.3 \\
\hline Married & 8 & 4.6 \\
\hline Divorced & 1 & 0.6 \\
\hline Widow & 1 & 0.6 \\
\hline \multicolumn{3}{|l|}{ Residence: } \\
\hline Rural & 69 & 39.4 \\
\hline Urban & 106 & 60.6 \\
\hline \multicolumn{3}{|l|}{ Class: } \\
\hline First & 62 & 35.4 \\
\hline Second & 40 & 22.9 \\
\hline Third & 36 & 20.6 \\
\hline Fourth & 37 & 21.1 \\
\hline \multicolumn{3}{|l|}{ Working with the study: } \\
\hline Yes & 38 & 21.7 \\
\hline No & 137 & 78.3 \\
\hline
\end{tabular}

Table (2): Distribution of nursing students by experiencing interpersonal sources of stress:

\begin{tabular}{|l|c|c|c|c|}
\hline \multicolumn{1}{|c|}{ Interpersonal Sources of stress } & \multicolumn{2}{c|}{ Yes } & \multicolumn{2}{c|}{ No } \\
\cline { 2 - 5 } & No. & \% & No. & \% \\
\hline Finding new friend & 80 & 45.7 & 95 & 54.3 \\
\hline Work with people they don't know & 78 & 44.6 & 97 & 55.4 \\
\hline Roommate conflict & 82 & 46.9 & 93 & 53.1 \\
\hline Change in social activities & 108 & 61.7 & 67 & 38.3 \\
\hline Fight with boyfriend/girlfriend & 99 & 56.6 & 76 & 43.4 \\
\hline Trouble with parents & 76 & 43.4 & 99 & 56.6 \\
\hline
\end{tabular}

Table (3): Distribution of nursing students by experiencing intrapersonal sources of stress

\begin{tabular}{|l|c|c|c|c|}
\hline \multicolumn{1}{|c|}{ Intrapersonal Sources of stress } & \multicolumn{2}{c|}{ Yes } & \multicolumn{2}{c|}{ No } \\
\cline { 2 - 5 } & No. & $\%$ & No. & \multicolumn{1}{c|}{$\%$} \\
\hline New responsibilities & 154 & 88.0 & 21 & 12.0 \\
\hline Started college & 126 & 72.0 & 49 & 28.0 \\
\hline Change in sleeping habits & 129 & 73.7 & 46 & 26.3 \\
\hline Change in eating habits & 116 & 663 & 59 & 33.7 \\
\hline Outstanding personal achievement & 95 & 543 & 80 & 45.7 \\
\hline Financial difficulties & 92 & 52.6 & 83 & 47.4 \\
\hline Spoke in public & 80 & 45.7 & 95 & 54.3 \\
\hline Change in religious beliefs & 37 & 21.1 & 138 & 78.9 \\
\hline
\end{tabular}




\begin{tabular}{|l|c|c|c|c|}
\hline \multicolumn{1}{|c|}{ Intrapersonal Sources of stress } & \multicolumn{2}{c|}{ Yes } & \multicolumn{2}{c|}{ No } \\
\cline { 2 - 5 } & No. & $\%$ & No. & \% \\
\hline Minor law violation & 72 & 41.1 & 103 & 58.9 \\
\hline Decline in personal health & 93 & 53.1 & 82 & 46.9 \\
\hline Held a job & 68 & 38.9 & 107 & 61.1 \\
\hline Change in use of alcohol or drugs & 39 & 22.3 & 136 & 77.7 \\
\hline Engagement/Marriage & 65 & 37.1 & 110 & 62.9 \\
\hline Death of a family member & 65 & 37.1 & 110 & 62.9 \\
\hline Death of a friend & 65 & 37.1 & 110 & 62.9 \\
\hline Severe injury & 74 & 42.3 & 101 & 57.7 \\
\hline
\end{tabular}

Table (4): Distribution of nursing students by experiencing academic sources of stress

\begin{tabular}{|l|c|c|c|c|}
\hline \multicolumn{1}{|c|}{ Academic sources of stress } & \multicolumn{2}{c|}{ Yes } & \multicolumn{2}{c|}{ No } \\
\cline { 2 - 5 } & No. & \% & No. & \% \\
\hline Increased class workload & 151 & 86.3 & 24 & 13.7 \\
\hline Lower grade than anticipated & 152 & 86.9 & 23 & 13.1 \\
\hline Anticipation of graduation & 113 & 64.6 & 62 & 35.4 \\
\hline Search for graduate school/ job & 115 & 65.7 & 60 & 34.3 \\
\hline Missed too many classes & 105 & 60.0 & 70 & 40.0 \\
\hline Serious argument with instructor & 85 & 48.6 & 90 & 51.4 \\
\hline Change of major & 89 & 50.9 & 86 & 49.1 \\
\hline Transferred schools & 79 & 45.1 & 96 & 54.9 \\
\hline
\end{tabular}

Table (5): Distribution of nursing students by experiencing environment sources of stress:

\begin{tabular}{|l|c|c|c|c|}
\hline \multicolumn{1}{|c|}{ Environment sources of stress } & \multicolumn{2}{c|}{ Yes } & \multicolumn{2}{c|}{ No } \\
\cline { 2 - 5 } & No. & $\%$ & No. & \multicolumn{2}{c|}{$\%$} \\
\hline Placed in unfamiliar situation & 108 & 61.7 & 67 & 38.3 \\
\hline Waited in long line & 96 & 54.9 & 79 & 45.1 \\
\hline Car trouble & 125 & 71.4 & 50 & 28.6 \\
\hline Vacations/breaks & 105 & 60.0 & 70 & 40.0 \\
\hline Change in living environment & 110 & 62.9 & 65 & 37.1 \\
\hline Messy living conditions & 113 & 64.6 & 62 & 35.4 \\
\hline Computer problems & 76 & 43.4 & 99 & 56.6 \\
\hline Put on hold for extended period of time & 72 & 41.1 & 103 & 58.9 \\
\hline Quit job & 42 & 24.0 & 133 & 76.0 \\
\hline Divorce between parents & 49 & 28.0 & 126 & 72.0 \\
\hline
\end{tabular}

Table (6): Comparison of the mean scores of sources of stress among faculty of nursing students in various grades:

\begin{tabular}{|c|c|c|c|c|c|c|}
\hline \multirow{3}{*}{$\begin{array}{c}\text { Sources of } \\
\text { stress }\end{array}$} & \multirow{3}{*}{ Score } & \multicolumn{4}{|c|}{ Grades } & \multirow{3}{*}{ P-value } \\
\hline & & First & Second & Third & Fourth & \\
\hline & & Mean \pm SD & Mean \pm SD & Mean \pm SD & Mean \pm SD & \\
\hline $\begin{array}{l}\text { Interpersonal } \\
\text { Sources }\end{array}$ & 6 & $3.32 \pm 1.49$ & $3.05 \pm 1.47$ & $2.31 \pm 1.82$ & $3.03 \pm 2.07$ & $0.043 *$ \\
\hline $\begin{array}{l}\text { Intrapersonal } \\
\text { Sources } \\
\end{array}$ & 16 & $8.42 \pm 2.87$ & $7.28 \pm 2.81$ & $7.00 \pm 3.14$ & $8.24 \pm 3.19$ & 0.067 \\
\hline $\begin{array}{l}\text { Academic } \\
\text { sources }\end{array}$ & 8 & $5.08 \pm 1.69$ & $5.15 \pm 1.64$ & $4.78 \pm 1.77$ & $5.30 \pm 1.78$ & 0.621 \\
\hline $\begin{array}{l}\text { Environment } \\
\text { sources }\end{array}$ & 10 & $5.71 \pm 2.06$ & $4.58 \pm 1.92$ & $4.47 \pm 2.31$ & $5.35 \pm 2.26$ & $0.013^{*}$ \\
\hline
\end{tabular}


Table (7): Distribution of coping strategies among faculty of nursing students:

\begin{tabular}{|c|c|c|c|c|c|c|}
\hline \multirow{2}{*}{ Coping strategies } & \multicolumn{2}{|c|}{ Never/ seldom } & \multicolumn{2}{|c|}{ Sometimes } & \multicolumn{2}{|c|}{ Often/always } \\
\hline & No. & $\%$ & No. & $\%$ & No. & $\%$ \\
\hline \multicolumn{7}{|l|}{ I. Ventilating feelings: } \\
\hline Say mean things to people, be sarcastic & 112 & 64.0 & 54 & 30.9 & 9 & 5.1 \\
\hline Swear & 119 & 68.0 & 44 & 25.1 & 12 & 6.9 \\
\hline Let off steam by complaining to your friends & 47 & 26.9 & 95 & 54.3 & 33 & 18.9 \\
\hline Get angry and yell at people & 64 & 36.6 & 93 & 53.1 & 18 & 10.3 \\
\hline $\begin{array}{l}\text { Let off steam by complaining to family } \\
\text { members }\end{array}$ & 49 & 28.0 & 75 & 42.9 & 51 & 29.1 \\
\hline Cry & 35 & 20.0 & 62 & 35.4 & 78 & 44.6 \\
\hline \multicolumn{7}{|l|}{ II. Seeking Diversions: } \\
\hline Go to a movie & 131 & 74.9 & 26 & 14.9 & 18 & 10.3 \\
\hline Play video games & 88 & 50.3 & 57 & 32.6 & 30 & 17.1 \\
\hline Use drugs & 93 & 53.1 & 47 & 26.9 & 35 & 20.0 \\
\hline Listen to music- stereo & 45 & 25.7 & 61 & 34.9 & 69 & 39.4 \\
\hline Read & 39 & 22.3 & 92 & 52.6 & 44 & 25.1 \\
\hline Go to shopping buy things you like & 33 & 18.9 & 84 & 48.0 & 58 & 33.1 \\
\hline Watch T. V & 38 & 21.7 & 86 & 49.1 & 51 & 29.1 \\
\hline Sleep & 35 & 20.0 & 73 & 41.7 & 67 & 38.3 \\
\hline \multicolumn{7}{|l|}{ III. Relaxing: } \\
\hline Work on a hobby & 51 & 29.1 & 84 & 48.0 & 40 & 22.9 \\
\hline Eat food & 32 & 18.3 & 76 & 43.4 & 67 & 38.3 \\
\hline Daydream & 43 & 24.6 & 70 & 40.0 & 62 & 35.4 \\
\hline Ride around in the car & 95 & 54.3 & 54 & 30.9 & 26 & 14.9 \\
\hline \multicolumn{7}{|l|}{ IV. Self-Reliance: } \\
\hline Get a job or work harder & 48 & 27.4 & 76 & 43.4 & 51 & 29.1 \\
\hline Try to think of the good things & 20 & 11.4 & 78 & 44.6 & 77 & 44.0 \\
\hline Try to make your own decisions & 24 & 13.7 & 55 & 31.4 & 96 & 54.9 \\
\hline Organize your life and what you have to do & 23 & 13.1 & 82 & 46.9 & 70 & 40.0 \\
\hline Get more involved in activities in school & 72 & 41.1 & 68 & 38.9 & 35 & 20.0 \\
\hline Tell yourself the problem(s) is not important & 51 & 29.1 & 93 & 53.1 & 31 & 17.7 \\
\hline \multicolumn{7}{|l|}{ V. Developing Social Support: } \\
\hline Blame others for what's going on & 62 & 35.4 & 93 & 53.1 & 20 & 11.4 \\
\hline Apologize to people & 27 & 15.4 & 89 & 50.9 & 59 & 33.7 \\
\hline Try to help other people solve their problems & 22 & 12.6 & 71 & 40.6 & 82 & 46.9 \\
\hline $\begin{array}{l}\text { Try to keep up friendships or make new } \\
\text { friends }\end{array}$ & 23 & 13.1 & 59 & 33.7 & 93 & 53.1 \\
\hline Say nice things to others & 26 & 14.9 & 56 & 32.0 & 93 & 53.1 \\
\hline Talk to a friend about how you feel & 34 & 19.4 & 76 & 43.4 & 65 & 37.1 \\
\hline
\end{tabular}

Table (7): Cont.

\begin{tabular}{|l|c|c|c|c|c|c|}
\hline \multicolumn{1}{|c|}{ Coping strategies } & \multicolumn{2}{c|}{ Never/ seldom } & \multicolumn{2}{c|}{ Sometimes } & \multicolumn{2}{c|}{ Often/always } \\
\cline { 2 - 7 } & No. & $\%$ & No. & $\%$ & No. & $\%$ \\
\hline \hline VI. Solving Family Problems: & & & & & & \\
\hline Talk to your father about what bothers you & 53 & 30.3 & 72 & 41.1 & 50 & 28.6 \\
\hline $\begin{array}{l}\text { Try to reason with parents and talk things out, } \\
\text { compromise }\end{array}$ & 42 & 24.0 & 74 & 42.3 & 59 & 33.7 \\
\hline Go along with parent's requests and rules & 22 & 12.6 & 76 & 43.4 & 77 & 44.0 \\
\hline Do things with your family & 23 & 13.1 & 79 & 45.1 & 73 & 41.7 \\
\hline Talk to a brother or sister about how you feel & 35 & 20.0 & 70 & 40.0 & 70 & 40.0 \\
\hline
\end{tabular}




\begin{tabular}{|c|c|c|c|c|c|c|}
\hline \multirow{2}{*}{ Coping strategies } & \multicolumn{2}{|c|}{ Never/ seldom } & \multicolumn{2}{|c|}{ Sometimes } & \multicolumn{2}{|c|}{ Often/always } \\
\hline & No. & $\%$ & No. & $\%$ & No. & $\%$ \\
\hline Talk to your mother about what bothers you & 44 & 25.1 & 68 & 38.9 & 63 & 36.0 \\
\hline \multicolumn{7}{|l|}{ VII. Avoiding: } \\
\hline Smoke & 123 & 70.3 & 24 & 13.7 & 28 & 16.0 \\
\hline Use drugs prescribed by doctor & 86 & 49.1 & 65 & 37.1 & 24 & 13.7 \\
\hline Try to stay away from home as much as possible & 77 & 44.0 & 60 & 34.3 & 38 & 21.7 \\
\hline Try to see the good things in a difficult situation & 37 & 21.1 & 78 & 44.6 & 60 & 34.3 \\
\hline Drink beer, wine, liquor & 133 & 76.0 & 21 & 12.0 & 21 & 12.0 \\
\hline \multicolumn{7}{|l|}{ VIII. Seeking Spiritual Support: } \\
\hline Talk to a minister/priest/ rabbi & 36 & 20.6 & 49 & 28.0 & 90 & 51.4 \\
\hline Go to mosque & 79 & 45.1 & 65 & 37.1 & 31 & 17.7 \\
\hline Pray & 39 & 22.3 & 38 & 21.7 & 98 & 56.0 \\
\hline \multicolumn{7}{|l|}{ X. Investing in Close Friends: } \\
\hline Be close with someone you care about & 23 & 13.1 & 62 & 35.4 & 90 & 51.4 \\
\hline Be with a boy friend or girlfriend & 24 & 13.7 & 68 & 38.9 & 83 & 47.4 \\
\hline \multicolumn{7}{|l|}{ IX. Seeking Professional Support: } \\
\hline Get professional counseling & 60 & 34.3 & 85 & 48.6 & 30 & 17.1 \\
\hline $\begin{array}{l}\text { Talk to a teacher or counselor at school about } \\
\text { what bothers you }\end{array}$ & 90 & 51.4 & 59 & 33.7 & 26 & 14.9 \\
\hline \multicolumn{7}{|l|}{ XI. Engaging in Demanding Activity: } \\
\hline $\begin{array}{l}\text { Do a strenuous physical activity (jogging, biking, } \\
\text { etc }\end{array}$ & 63 & 36.0 & 74 & 42.3 & 38 & 21.7 \\
\hline $\begin{array}{l}\text { Try, on your own, to figure out how to deal with } \\
\text { your problems or tension }\end{array}$ & 28 & 16.0 & 87 & 49.7 & 60 & 34.3 \\
\hline $\begin{array}{l}\text { Try to improve yourself (get body in shape, get } \\
\text { better grades, etc.) }\end{array}$ & 21 & 12.0 & 75 & 42.9 & 79 & 45.1 \\
\hline Work hard on school work or school projects & 59 & 33.7 & 79 & 45.1 & 37 & 21.1 \\
\hline \multicolumn{7}{|l|}{ XII. Being Humorous: } \\
\hline Joke and keep a sense of humor & 36 & 20.6 & 75 & 42.9 & 64 & 36.6 \\
\hline Try to be funny and make light of it all & 25 & 14.3 & 78 & 44.6 & 72 & 41.1 \\
\hline
\end{tabular}

Table (8): Comparison of coping strategies among faculty of nursing students in various grades:

\begin{tabular}{|l|c|c|c|c|c|}
\hline \multirow{2}{*}{\multicolumn{1}{c|}{ Coping strategies }} & \multicolumn{3}{c|}{ Grades } & \multirow{2}{*}{ P-value } \\
\cline { 2 - 6 } & First & Second & Third & Fourth & \\
\cline { 2 - 6 } & Mean \pm SD & Mean \pm SD & Mean \pm SD & Mean \pm SD & \\
\hline Ventilating feelings & $4.55 \pm 2.10$ & $4.98 \pm 1.58$ & $4.58 \pm 2.32$ & $4.84 \pm 2.08$ & 0.718 \\
\hline Seeking Diversions & $7.92 \pm 2.97$ & $7.48 \pm 2.75$ & $6.22 \pm 2.02$ & $6.92 \pm 3.17$ & $0.029 *$ \\
\hline Relaxing & $4.10 \pm 1.69$ & $4.03 \pm 1.93$ & $3.50 \pm 1.78$ & $3.59 \pm 1.79$ & 0.297 \\
\hline Self-Reliance & $6.58 \pm 2.49$ & $7.10 \pm 2.84$ & $6.86 \pm 2.49$ & $6.30 \pm 2.57$ & 0.549 \\
\hline Developing Social Support & $6.82 \pm 2.59$ & $7.13 \pm 2.83$ & $7.72 \pm 2.34$ & $7.62 \pm 2.79$ & 0.312 \\
\hline Solving Family Problems & $6.52 \pm 3.37$ & $7.80 \pm 3.41$ & $7.11 \pm 2.73$ & $6.78 \pm 3.28$ & 0.262 \\
\hline Avoiding & $3.42 \pm 1.82$ & $3.83 \pm 2.17$ & $2.94 \pm 1.88$ & $3.22 \pm 2.37$ & 0.287 \\
\hline Seeking Spiritual Support & $3.23 \pm 1.44$ & $3.45 \pm 1.48$ & $3.28 \pm 1.34$ & $3.62 \pm 1.78$ & 0.608 \\
\hline Investing in Close Friends & $2.56 \pm 1.30$ & $2.78 \pm 1.39$ & $2.97 \pm 1.13$ & $2.68 \pm 1.40$ & 0.510 \\
\hline Seeking Professional Support & $1.35 \pm 1.15$ & $1.98 \pm 1.31$ & $1.11 \pm 1.14$ & $1.43 \pm 1.21$ & $0.014 *$ \\
\hline Engaging in Demanding Activity & $4.47 \pm 1.84$ & $4.33 \pm 2.10$ & $3.97 \pm 1.61$ & $4.05 \pm 2.13$ & 0.577 \\
\hline Being Humorous & $2.45 \pm 1.33$ & $2.48 \pm 1.36$ & $2.53 \pm 1.18$ & $2.24 \pm 1.46$ & 0.807 \\
\hline
\end{tabular}


Table (1) shows socio-demographic characteristics of the studied sample. It was found that age of students ranged between $18-30$ years with mean \pm SD of $20.34 \pm 2.05(18-30)$. Most of students were females $(90.9 \%)$, single $(94.3 \%)$, and residing in urban areas $(60.6 \%)$ ). $35.4 \%$ and $78.3 \%$ of them were in the first class and did not work with the study respectively.

Regarding to sources of stress (stressors), findings revealed that the most common interpersonal sources of stress were "change in social activities" (61.7\%) and fight with boyfriend/girlfriend (56.6\%) as revealed in table (2). The most common intrapersonal sources of stress were new responsibilities $(88.0 \%)$, change in sleeping habits $(73.7 \%)$, started college $(72.0 \%)$ and change in eating habits (66.3\%) as shown in table (3).

Table (4) clarifies that the most common academic sources of stress were lower grade than anticipated $(86.9 \%)$, increased class workload $(86.3 \%)$ and search for graduate school/ job $(65.7 \%)$.

Concerning the environmental sources of stress, students reported that, car trouble $(71.4 \%)$, messy living conditions (64.6\%), change in living environment $(62.9 \%)$ and placed in unfamiliar situation $(61.7 \%)$ were the most frequent sources of stress table (5).

The mean scores of interpersonal, intrapersonal and environmental sources of stress were higher among first grade students than other grades. They were 3.32 $\pm 1.49,8.42 \pm 2.87$ and $5.71 \pm 2.06$ respectively. However, the mean score of academic sources of stress was higher among fourth grade students. It was $5.30 \pm 1.78$ as revealed in table (6). Statistically significant differences were found between various grade students in relation to interpersonal and environmental sources of stress ( $p$ value was 0.043 and 0.013).

Table (7) shows distribution of coping strategies among faculty of nursing students. It was found that, more than half of students reported seldom or never saying mean things to people, being sarcastic (64.0\%) and "swearing" (68.0\%). Also, more than half reported sometimes the let off steam by complaining to their friends $(54.3 \%)$ and get angry and yell at people $(53.1 \%)$. While, $44.6 \%$ reported often or always employ "crying". In the area of seeking diversion, $(74.9 \%, 53.1 \%$ and $50.3 \%$ ) reported seldom or never go to a movie, use drugs and play video games respectively. While, $52.6 \%$ and $49.1 \%$ reported sometimes read and watch $\mathrm{T}$. V.

Concerning to relaxing, $48.0 \%$ and $43.4 \%$ reported sometimes work on a hobby and eat food. In the area of self reliance, $53.1 \%$ and $46.9 \%$ reported sometimes tell themselves the problem(s) is not important and organize their life and what they have to do. While, $54.9 \%$ and $44.0 \%$ try to make their own decisions and try to think of the good things often or always. In relation to developing Social Support, $53.1 \%$ and $50.9 \%$ reported sometimes blame others for what's going on and apologize to people. More over, $53.1 \%$ reported try to keep up friendships or make new friends and say nice things to others often or always.

As regards solving family problems: $45.1 \%$ and $42.3 \% \%$ reported sometimes do things with their family and try to reason with parents and talk things out, compromise and reported often go along with parent's requests and rules. Concerning avoiding, $76.0 \%$ and $70.3 \%$ reported seldom or never drink beer, wine, liquor and smoke. While, $44.6 \%$ reported sometimes try to see the good things in a difficult situation. Regarding seeking spiritual support, $45.1 \%$ reported seldom or never go to mosque while, $56.0 \%$ and $51.4 \%$ pray and talk to a minister/priest/ rabbi. In the area of investing in close friends, $51.4 \%$ and $47.4 \%$ reported are close with someone he or she cares about and be with a boy friend or girlfriend often.

In relation to seeking professional support, $51.4 \%$ reported seldom or never talk to a teacher or counselor at school about what bothers them and $48.6 \%$ reported sometimes get professional counseling. Regarding engaging in demanding activity, $49.7 \%$ and $45.1 \%$ reported sometimes try, on your own, to figure out how to deal with your problems or tension and work hard on school work or school projects and $45.1 \%$ reported try to improve themselves (get body in shape, get better grades, etc.) often. In the area of being humorous, $44.6 \%$ and $42.9 \%$ reported sometimes try to be funny and make light of it all, joke and keep a sense of humor.

Comparison of coping strategies among faculty of nursing students in various grades is illustrated in table (8). It was found that first grade students used seeking diversions, relaxing and engaging in demanding activities more than other coping strategies. However, the second grade students employed ventilating feelings, self-reliance, solving family problems, avoiding and seeking professional support. As regards third grade students, they used developing social support, investing in close friends and being humorous. While, fourth grade students utilized seeking spiritual support. There are statistically significant differences between various grade students regarding use of seeking diversions and seeking professional support as coping strategies ( $\mathrm{p}$ value $=0.029 \& 0.014)$ respectively . 


\section{Discussion}

The current study revealed that, the most common stressors among faculty of nursing students were intrapersonal and academic stressors. The most frequently reported stressors new responsibilities, lower grade than anticipated, increased class workload, change in sleeping habits, started college. This could be attributed to that responsibilities in the university are different and difficult than those in the secondary schools as there is clinical training in labs and hospitals. Also, studying by credit hours is considered overloading for students because some subjects are depend on others before registration as well as other activities/homework which distributed on students.

This result is partially supported by that of (Goff, 2011) who reported high levels of both personal and academic stressors were found, but were not significant predictors of academic performance. Also, the result is to some extent supported by Ross (1999) who found intrapersonal sources of stress were the most common while; Evans \& Kelly (2004) found that examinations, the intense amount of work, and finding the academic work difficult were the most important source of stress.

Other study reported that nursing students experience academic stressors, clinical stressors, and external or everyday stressors (Jimenez et al, 2010).

The current result is somewhat contradicted with Seyedfatemi et al., (2007) who found that interpersonal and environmental sources of stress were the most common, with the five most frequently reported stressors being finding new friends, new responsibilities, increased class workload, being placed in unfamiliar situations, and working with people they did not know, in that order and interpreted this result by that the most of these undergraduate students come from townships outside Tehran and study for 4 years in that city. They are therefore placed in unfamiliar surroundings, with crowded streets and other stressors endemic to a capital city. Thus, for these students, living in dormitories may cause more stress than for students who live in Tehran. In addition, this data was collected during the Fall Semester, when students are at the beginning of their courses, have the responsibility to do homework, have to start attending new clinical units for training. During their college years, students experience constant challenges and demands for adjustment and change along with academic pressures, students must take responsibility for themselves, must seek acceptance from their peers in a world of mixed values, and begin more intimate relationships. Mahat (1998) found that negative interpersonal relationships were the most frequently reported stressful event.

Nigerian nursing students have high levels of stress, with the most common stressors including excessive schoolwork, financial problems, inadequate recreational facilities, and overcrowded accommodations (Omigbodun et al., 2004). Also, this finding is in agreement with that of (Timmins \& Kaliszer, 2002). However, Birx and Baldwin (2002) reported that one of the greatest sources of stress in nursing school is reported by students who have to work with staff who are not welcoming or helpful, and that one of the keys to conduct learning is to promote good staff-student relationships.

The first grade students experienced more interpersonal, intrapersonal and environmental sources of stressors than other grade students. However, fourth grade students reported more academic sources of stress. This might be related to new situations which they face in the university and differ greatly than those in the secondary schools as well as to inability to cope with those situations. This finding is partially in agreement with that of Seyedfatemi et al., (2007) who found that first-year students experienced greater stress than students in subsequent years. In this aspect, Misra \& McKeen (2000) found that students at the freshman and sophomore levels experienced more stress than juniors or seniors.

More than half of students reported that the most often used coping strategies to cope with stressors were praying, trying to keep friendships, saying nice things to others, talking to rabbi and being close to someone who they care about. In addition, more than half reported sometimes they employed making their own decisions, complaining to friends, get angry or yell to people, tell themselves problem(s) is not important and blame others. This could be explained by the regional, cultural background and religious as in Arabian and Islamic cultures; people are using praying and other religious activities to deal with stress more than other coping strategies. Also, people are sociable and they emphasize on social relationships on childrearing.

This finding is greatly supported by Seyedfatemi et al., (2007) who found that the most commonly used coping strategies are, in order: going along with one's parents requests and rules, praying, making one's own decisions, apologizing, helping other people to solve problems, keeping friendships and daydreaming and interpreted the finding by that; In Iran, the family is important, both culturally and religiously, with religiosity being the most striking cultural feature in the country. Thus, respecting one's family's rules, parents' requests and praying are emphasized in childrearing. Every Muslim learns prayer from 
childhood and prays five times daily. In addition, Iranians are very social and emotional people, so that helping each other, maintaining friendships and complimentary rituals such as apologizing are prominent attributes of Iranians.

Bahri (2010) found that the top five coping strategies that frequently used by the students were religion, active coping, positive reinterpretation, planning, and use of instrumental support, however, the main coping strategy was religion. These strategies are positive coping strategies which have been reported in studies as very adaptive and hasten the recovery from distress Myers (2005) \& Carver (1997).

Among Black and Latino students, the most frequently reported coping strategies were talking with friends, talking with parents, and participating in religious and social activities (Chiang et al., 2004). In addition, a majority of students were found to utilize the "seeking social support" category of coping more than others. Among pre-registration diploma nursing students in Ireland, talking to relatives and friends and talking to peers were the most common methods of coping with stress as reported by Evans \& Kelly (2004).

Nursing students in the present study reported that they never or seldom used drinking beer, wine, liquor, going to movie, swear, be sarcastic, using drugs and playing video games. This may be related to cultural believes, values and religion which prohibit such behaviors as the study was carried out in upper Jordan in which respecting believes and values play an important role.

The current result is partially supported by Seyedfatemi et al., (2007) who found that the least common coping strategies used by nursing students were, in order, smoking, drinking, using prescribed drugs, getting professional counseling, going to movies, playing video games, talking to a counselor, talking to a priest, and staying away from home. Although many studies have found high smoking and drinking rates among students, these rates are low in Iranian students (Gostautas etal., 2007\& Watson et al., 2006). This may be related to the religious beliefs of students, which prohibit such behaviors. While talking to a counselor and getting professional counseling are cultural behaviors, many people may refuse professional help, except for severe problems. In contrast, $24.6 \%$ of Black and Latino students indicated that they would talk to a counselor about their concerns (Chiang et al., 2004).

\section{Recommendation:}

Psycho educational program about stress management techniques is essential to help students manage their stressors effectively.

\section{References:}

1. Bahri MS (2010): Stress, stressors and coping strategies among secondary school students in a Malaysian Government Secondary School: Initial Findings ASEAN Journal of Psychiatry, Vol.11 (2) July - December 2010: 1- 15.

2. Barling J: Employment (1990): stress and family functioning. New York: John Wiley \& Sons.

3. Birx, E., \& Baldwin, S. (2002): Nurturing staffstudent relationships. Journal of Nursing Education, 41, 86-88.

4. Carver CS (1997): You want to measure coping but your protocol too long: Consider the Brief COPE, International Journal of Behavioural Medicine, 4 (1): 92-100.

5. Chiang L, Hunter CD, Yeh CJ (2004): Coping attitudes, sources, and practices among Black and Latino college students. Adolescence, 39(156):793-815.

6. Day AL, Livingstone HA (2004): Gender differences in perceptions of stressors and utilization of social support among university students. Canadian Journal of Behavioral Science, 35 (2):73-83.

7. Evans W, Kelly B (2004): Pre-registration diploma student nurse stress and coping measures. Nurse Education Today 24 (6):473482.

8. Goff; Anne-Mari (2011): Stressors, academic performance, and learned resourcefulness in baccalaureate nursing students. International Journal of Nursing Education Scholarship, Vol. 8 [, Iss. 1, Art. 1, 8 .

9. Gostautas A, Povilaitis R, Pilkauskiene I, Jakusovaite I, Statkeviciene S (2007): The peculiarities of use of addictive substances among students during 2005-2006. Medicina (Kaunas) 43(2):153-160.

10. Jimenez C, Navia-Osorio PM, Diaz CV (2010): Stress and health in novice and experienced nursing students. J Adv Nurs. 66 (2):442-455.

11. Mahat G (1998): Stress and coping: junior baccalaureate nursing students in clinical settings. Nursing Forum, 33 (1):11-19.

12. Misra R, McKean M (2000): College students' academic stress and its relation to their anxiety, time management, and leisure satisfaction. American Journal of Health Studies, 16 (1):4151.

13. Myers DG (2005): Stress and Health, in: Exploring Psychology. 6th ed. New York, Worth Publishers. 
14. Nicholl H, Timmins F (2005): Programmerelated stressors among part-time undergraduate nursing students. Journal of Advanced Nursing, 50 (1):93-100.

15. Omigbodun OO, Onibokun AC, Yusuf BO, Odukogbe AA, Omigbodun AO (2004): Stressors and counseling needs of undergraduate nursing students in Ibadan, Nigeria. Journal of Nursing Education, 43(9):412-415.

16. Pender, $\mathbf{N}$ (2002): Health promotion in Nursing Practice $\left(4^{\text {th }}\right.$ Ed.). Upper Saddele River, NJ: Prentice Hall.

17. Robin Walton L., A (2002): Comparison of Perceived Stress Levels and Coping Styles of Junior and Senior Students in Nursing and Social Work Programs. In Doctor of Education Dissertation. College of Graduate Studies, Marshall University.

18. Ross SE, Niebling BC, Heckert TM (1999): Sources of stress among college students. College Student Journal, 33(2):312-317.

19. Sadock, B J., Kaplan HI (2007): Synopsis of Psychiatry: behavioral sciences/clinical psychiatry. USA, Philadelphia. Lippincott Williams \& Wilkins Press.; Chap. 28: P. 815.

20. Shaher H.H (2012): Gender differences in stressors and reactions to stressors among Jordanian university students, Int $\mathrm{J}$ Soc Psychiatry January 2012vol. 58 no. 1 26-3.

21. Seyedfatemi, $M$, Tafreshi, $M$ and Hagani, $H$ (2007): Experienced stressors and coping strategies among Iranian nursing students. BMC Nursing, 6:11 doi:10.1186/1472-6955-6-11

22. Shields N (2001): Stress, active coping, and academic performance among persisting and nonpersisting students. Journal of Applied Biobehavioral Research, 6 (2):65-81.

23. Shriver CB \& Scott-Stiles A (2000): Health habits of nursing versus non-nursing students: a longitudinal study. Journal of Nursing Education, 39 (7):308-314.

24. Stranks J W (2005): Stress at work: management and prevention. ButterworthHeinemann Press: P. 7.

25. Tamina Toray (1998): Coping in Women College Students: The Influence of Experience. Journal of College Student Development.

26. Timby BK (2008): Fundamental nursing skills and concepts. USA, Philadelphia, Lippincott Williams \& Wilkins press.: P. 941.

27. Timmins, F., \& Kaliszer, M. (2002): Aspects of nurse education programmes that frequently cause stress to nursing students-fact finding sample survey. Nurse Education Today, 22, 203211.
28. Videbeck S L. (2007): Psychiatric mental health nursing. USA, Philadelphia, Lippincott Williams \& Wilkins press. Chap. 13: P. 242.

29. Watson H, Whyte R, Schartau E, Jamieson E (2006): Survey of student nurses and midwives: smoking and alcohol use. British Journal of Nursing, 15(22):1212-1216.

30. White L (2000): Foundations of Nursing: Caring for the Whole Person. USA.

31. Shields N (2001): Stress, active coping, and academic performance among persisting and non persisting students. Journal of Applied Biobehavioral Research, 6 (2):65-81 